\title{
7 \\ Selenium in Health and Disease IV: The Immune Response and Other Selenium-Related Conditions
}

\subsection{The Immune System}

The immune system is a collection of tissues, cells, and molecules whose prime physiological function is protection of the body against harmful influences, both external and internal, that can damage health. It is also involved in other functions, such as wound healing and removal of cells that have died through natural processes. In a restricted sense, immunity refers to mechanisms established by a host to resist disease after exposure to a foreign infectious agent. In a broader sense, it can also include hypersensitive biological phenomena of altered tissue reactivity such as allergies, acquired tolerance to-and rejection of - foreign tissues, and autoimmune diseases (Maurer, 1961).

There is evidence that selenium plays a part in many of the mechanisms of immunity. How it does so is still only partially understood and, because of the complexity of the processes involved, final answers to many, as yet unresolved, questions are unlikely to be found for some time. For some readers the language of immunity is largely unfamiliar and highly specialized, yet an understanding of it is useful for those who want to appreciate the role of selenium in human health. It is for this reason that the following brief overview of some of the principal elements in the body's immune system is given. It is hoped that it will help to clarify the picture for those who might otherwise be deterred from looking into what is, in fact, a very important and fascinating role of selenium. This introduction is largely based on the text by Staines et al. (1993).

\subsubsection{Components of the Immune System}

The mechanisms of immunity, like the language used to describe them, are complex. The body's immune system must always be in a state of alert, ready to defend it against infection. It is designed to give protection against several different classes of infective organisms, including viruses, bacteria, fungi, protozoa, and helminths. Although its processes are, to a large extent, dependent on lymphoid organs, such as thymus, spleen, and lymph nodes, the immune system does 
not operate in isolation in just one type of organ or tissue. It interacts dynamically with the endocrine, gastrointestinal, respiratory, and other tissues, and its cells are distributed throughout every part of the body.

The system operates at several levels. A first line of defense is its innate or natural immunity, which provides physical and chemical protection against infection. This is a function of skin and other epithelial and mucous membrane barriers in the gastrointestinal, respiratory, and urogenital tracts. The defensive processes include phagocytosis and killing of invading organisms, as well as secretion of enzymes, such as lysozymes and other compounds to form a chemical barrier against invasion. This level of immunity is nonspecific and is not always effective.

Organisms that manage to get through the first barrier are tackled by a variety of other agents. These include acute phase proteins, a mixed group of molecules that can attach themselves to invading materials and prepare them for phagocytosis. $C$-reactive proteins and lactoferrin are two of these proteins that are synthesized in the liver in response to inflammation at other sites. Another group of the acute phase proteins are the interferons, which increase the resistance of cells against viral attack. They function as cytokines or intercellular signaling molecules.

Two groups of phagocytotic cells ingest and destroy foreign materials that enter the cell. The first comprises polymorphonuclear neutrophil leucocytes (PMNs), or white blood cells (neutrophils). The second is the reticulo-endothelial system composed of monocytes found in the blood and macrophages found especially in the liver, kidney, spleen, and lymph nodes.

Phagocytosis is comparable to the mechanism whereby amebae eat food particles. Macrophages, for instance, recognize a foreign material, bind it to their cell membrane, and engulf it in a vacuole. Oxygen free radicals are generated within the vacuole and kill the entrapped microorganism, which is then digested by lysosomes. This is the final act of the body's first line of defense, the natural immune system. The foreign material is bound to the macrophages or neutrophils usually with the help of what is known as opsonization. This is a process in which the foreign particle is coated with specific antibodies and components of the complement system. This system is composed of a complex group of protein molecules working as a molecular cascade. They are involved in the control of inflammation and in the activation of phagocytes and lysis of cell membranes.

Phagocytes can also destroy invading organisms and other unwanted cells, including some types of tumor cells, directly without phagocytosis. This is done by a special type of lymphocyte, the large granular lymphocytes. These cytotoxic cells are known as natural killer (NK) cells.

Acquired or adaptive immunity is the body's secondary immune response. Unlike natural immunity, it is characterized by specific immunological memory. Acquired immunity takes place in a number of different cells and tissues. They include the lymphocytes, which are found in blood and lymph fluids and in organized lymphoid tissue. These cells recognize and react to antigens, proteins foreign to the organism that are capable of triggering formation of antibodies. Lymphocytes originate in bone marrow as lymphoid stem cells. They can develop into two different forms, $T$ cells and $B$ cells, depending on which developmental pathway they follow. 
Those that pass through the blood to the thymus gland before moving on to the lymph nodes and spleen are the T cells. In the thymus they mature and acquire antigen reactivity. This gives them the ability to recognize foreign antigens by means of the major histocompatibility complex $(\mathrm{MCH})$ molecules, known as $T$ cell receptors (TCRs), which react with antigens on their surface. TCRs are not specific for any one antigen, though they have considerable diversity in immunocompetence. T cells provide what is known as cell-mediated immunity.

The second type of lymphocyte, B cells, which are responsible for what is known as humoral immunity, do not pass through the thymus but settle directly in the lymph nodes and spleen. They acquire their name from the bursa of Fabricius, the tissue in which they are produced in chicks. B cells also have antibody protein receptor molecules on their surface, but unlike TCRs, these are specific for one antibody only. However, though they differ from each other in their development and response to antigens, both $\mathrm{T}$ and $\mathrm{B}$ cells cooperate closely with each other and form a combined defense against invading organisms.

B cell activation occurs when an antigen comes into contact with the cell and combines with an antibody receptor molecule on its surface. This generates signals within the cell that switch on antibody production and converts it into an antibodysecreting plasma cell. The cell then multiplies, differentiates into a clone of daughter cells, and starts a chain reaction, leading to the destruction of the invader.

The life of most of these daughter cells is short and ends when their work of secreting antibodies is done. A few, however, which do not take part in secreting antibodies, survive for up to several years. These are memory cells that can recognize the antigen responsible for their original formation if exposed to it once more. The same antibody is produced, but now at a faster rate, because in the meantime clonal expansion has resulted in the production of additional antigenreactive cells. This secondary immune response provides a highly efficient rapid response to antigen invasion, since it does not require the initial presence of large numbers of each specific leucocyte.

The antibodies secreted by B cells in response to antigens are immunoglobulins, one of several different groups of proteins that occur in blood. Between about a quarter and a half of the protein in human plasma is composed of a mixture of globulins. These can be separated by electrophoresis into six different categories, which includes the alpha-globulins ( $\alpha$-globulins) and the gammaglobulins ( $\gamma$-globulins). These latter are the immunoglobulins or antibodies.

Immunoglobulins consist of different types or classes of closely related molecules. The commonly used abbreviation for immunoglobulin is Ig, followed by a letter signifying the subclass, such as IgG and IgA. The most abundant of them in human plasma is IgG, making up about $80 \%$ of the total, with IgA next (13\%), followed by $\operatorname{IgM}, \operatorname{IgD}$, and $\operatorname{IgE}$ in lesser amounts.

The five principal classes of Ig are heterogeneous, and each class in its turn is made up of possibly thousands of individual immunoglobulins. Their molecular structure, comprising two small and two large polypeptide chains, accounts for their overall similarities and also their specific individuality. The sequence of amino acids at the site where the antigen binds to the $\mathrm{N}$-terminal end of each pair 
of polypeptide chains is variable and accounts for the unique specificity of each antibody. The C-terminal ends have a constant amino acid sequence and provide the basic framework that all Ig molecules require to carry out their functions (Montgomery et al., 1977).

Each antibody is manufactured by the body in response to a specific antigen. The Ig has the ability to recognize this antigen and combines with it tightly through specific bonds. The antigen-antibody reaction is analogous to the specificity and bonding of an enzyme to its substrate. Once the body has manufactured antibodies against a particular antigen, the procedure is recorded in the molecular memory of its cells and may never be forgotten in most cases.

The activation of $\mathrm{T}$ cells differs considerably from the process in $\mathrm{B}$ cells. Unlike B cells, they do not make antibodies or secrete special forms of their antigen receptor molecules when they react with antigen. However, like B cells, they do respond to activation by growth and differentiation. In addition, they secrete a number of different types of cytokines. These mediators are very important for regulating the function of other lymphocytes. Among these other cells are a number of different types of T cells that have special accessory molecules on their surfaces that allow them to perform a number of different functions. These cells include T-helper cells, which help B cells to make antibodies; T-suppressor cells, whose function is to suppress immune response and thus moderate it when necessary; and T-cytotoxic cells, which can destroy other cells that have been invaded by a virus. Another type of cell resulting from antigen reaction of T cells is the delayed-type hypersensitivity cell (Tdth, or THI), which can be involved in cell-mediated immune response, such as destruction of intracellular bacteria, autoimmune diseases, and rejection of tissue implants.

Other cells, in addition to $\mathrm{B}$ and $\mathrm{T}$ cells, are also involved in immune responses. Mast cells, which occur in large numbers in mucosal tissue, contain granules of pharmacologically active compounds. These have $\operatorname{IgE}$ antibodies on their surface and when, during an infection of the body, these bind to specific antigens, the cells are triggered to degranulate and release their contents. This causes local inflammation, which in turn calls neutrophils, monocytes, and lymphocytes to the site to oppose the infection. Basophils (basophilic polymorphonuclear leucocytes), which are related to neutrophils, contain similar granules and function in a similar manner to the mast cells. Eosinophils, also related to neutrophils, are particularly concerned with defense against parasites that are too large to be phagocytosed. They function by coating the parasite with IgG and $\operatorname{IgE}$ antibodies and destroy it outside the cell. These, and certain other cells with similar functions, are known as killer cells (K cells).

\subsubsection{The Role of Selenium in the Immune Response}

Adequate dietary selenium is known to be essential for optimum activity of virtually all arms of the immune system, though mechanisms of this requirement are not yet fully understood (Arthur et al., 2003). Selenium deficiency affects the efficiency of both the innate nonadaptive and the acquired adaptive immune systems 
(Spallholz, 1990; Turner and Finch, 1991; Kiremidjian-Schumacher and Roy, 1998; Brown and Arthur, 2001).

Selenium, however, is not the only nutrient required for the optimum function of the body's immune response to attack. A study of the development of the acquired immune system in chickens has shown that while deficiency of selenium on its own can impair bursal growth, stunting of the thymus occurs only when both selenium and vitamin $\mathrm{E}$ are inadequate (Marsh et al., 1986). Thus, it appears that while deficiency of both vitamin $\mathrm{E}$ and selenium blocks the normal flow of inductive signals from epithelial cells to the developing lymphocytes, B cells are more vulnerable than $\mathrm{T}$ cells to selenium deficiency. The effect of selenium deficiency on antibody production appears to be age-dependent. When the mitogen sheep red blood cell (SRBC) was used to assess immune response in vitro, 2-week-old chicks maintained on a selenium-deficient diet had reduced antibody titres, whereas 3-week-old chicks only showed a reduction when they were both selenium- and vitamin E-deficient (Marsh et al., 1986).

Studies on a number of different animal species, both ruminants and nonruminants, have shown that not all classes of antibodies are affected to the same extent by selenium deficiency (Larsen, 1993). It has been found to impair the proliferation of both $\mathrm{T}$ and $\mathrm{B}$ cell lymphocytes in response to mitogens as well as the activity of NK cells and lymphokine-activated killer cells (KiremidjianSchumacher et al., 1994). The humoral system is also adversely affected, with decreased production of, for example, IgG and IgM titre in humans. Supplementation with selenium results in improvements in these processes. Mice given a low-selenium diet, with adequate vitamin $\mathrm{E}$, had reduced $\mathrm{IgG}$, but had normal IgM responses to SRBC mitogen. However, when the deficient diet was continued into the second generation, IgM-producing cells also became affected (Mulhern et al., 1985).

Differences in animal species, age, sex, and antigen have also been found to affect the degree to which antibody production responds to selenium supplementation. Early experiments appeared to indicate that high concentrations of selenium are necessary to boost IgG and IgM antibody response (Spallholz et al., 1975). However, it has been shown that supplementation at the supranutritional level may not be necessary to do this. Levels required appear to depend on species and antigen. In the case of lambs, for example, selenium at a level of $0.1 \mu \mathrm{g} / \mathrm{g}$ in the diet gave a better antibody response to parainfluenza-3 virus than did a dose of $1.0 \mu \mathrm{g} / \mathrm{g}$ in response to tetanus toxin (Larsen et al., 1988). A difference in antibody response to toxins has been shown between lambs and certain other animals. Supplementation with both vitamin E and selenium was found to be necessary in cattle and horses to increase their antibody response to Pasteurella haemolytica and certain other toxins, but no such additive effect of the two micronutrients was observed in lambs (Larsen, 1993).

Tests using phytolectin mitogens of different types to investigate the effect of selenium on the proliferative response of $\mathrm{T}$ and $\mathrm{B}$ cells have confirmed that selenium deficiency affects the immune systems of different animal species in different ways. While, for example, the antibody response of $\mathrm{T}$ cells to Concanavalin 
A (Con A) was increased in selenium-deficient chickens and pigs (Larsen and Tollersrud, 1981; Marsh et al., 1987), as well as in marginally deficient humans (Arvilommi et al., 1983), it was depressed in sheep (Larsen et al., 1988). Deficiency of both selenium and vitamin E depressed T-cell response to mitogens more severely than did selenium deficiency alone in chicks and rats (Eskew et al., 1985; Marsh et al., 1987).

Adult ruminants appear to be more resistant than their young to the effects of selenium deficiency on lymphocyte response to mitogens (Turner and Finch, 1991). Ewes with combined vitamin $\mathrm{E}$ and selenium deficiencies responded well to phytohemoglutinin (PHA), but their lambs did not and their T cell reactivity ultimately failed (Turner and Finch, 1990). It may be that this difference is due to the high levels of selenium that can be concentrated in the rumens of adult sheep, almost 50 times higher than levels in their dry diet (Whanger et al., 1978) and, consequently, to the difference in availability of microbial selenium to lymphocytes in lambs and ewes.

Failure of lymphocyte response to mitogens in selenium-deficient lambs is easily reversed by the provision of supplementary selenium. However, the amount of the element used can affect the outcome significantly. While in vitro studies have shown that doses even less than $1 \mathrm{ng} / \mathrm{ml}$ are sufficient to enhance the response in selenium-deficient lambs to PHA, when the dose was increased to $10 \mathrm{ng} / \mathrm{ml}$, the response plateaued out and above $1 \mu \mathrm{g} / \mathrm{ml}$ toxic effects were observed (Turner and Finch, 1990). A similar concentration-related effect has been found to occur in human lymphocytes stimulated with PHA. When the selenium concentration in the culture medium was increased, the risk of chromosomal aberrations was found to be increased significantly (Khalil, 1989).

\subsubsection{Selenium and the Immune Response to Infection}

It is well established that selenium plays a role in the defense systems of animals against bacteria and other infectious agents (Boyne et al., 1984). Selenium deficiency has been shown to impair in vitro the ability of neutrophils and macrophages to kill ingested cells of the yeast Candida albicans (Boyne and Arthur, 1986). This impairment is associated with changes in enzymes and structures in the cells (Serfass and Ganther, 1975).

As has been noted by Arthur et al. (2003), one of the most widely investigated associations between selenium and the immune system is the effect of the element on neutrophil function. Reactive oxygen species produced by neutrophils play a major role in the destruction of invading microorganisms. However, these free radicals, if not scavenged by GPX once their primary role has been completed, can destroy the very neutrophils that produce them.

A balance must be maintained between production of sufficient radicals to kill invaders and the enzyme systems that protect the neutrophils from the same radicals. This balance can be upset by selenium deficiency. This does not actually affect production of neutrophils in a number of different animal species, but it can interfere with their function (Turner and Finch, 1991). Neutrophils from 
selenium-deficient mice, rats, and cattle, for instance, have been shown to be able to ingest pathogens in vitro, but are unable to kill them as efficiently as neutrophils from selenium-sufficient animals can (Boyne and Arthur, 1986). Evidence from in vitro experiments that investigated production of superoxide by neutrophils from selenium-deficient mice stimulated with phorbal myristate acetate supports the view that the inability to destroy pathogens is related to decreased activity of GPX1 in the neutrophils. This allows the free radicals produced in the respiratory burst to kill the neutrophils themselves.

The effect of selenium on GPX activity is not the only selenium-related function involved in neutrophil activity. In vitro studies that investigated the response of selenium-deficient mice to $C$. albicans found evidence that neutrophil candidacidal activity has a biphasic pattern (Boyne and Arthur, 1986). When very low doses of selenium were given to deficient mice, candidacidal activity increased from approximately 9 to $14 \%$. Additional supplementation did not increase this activity until much higher doses were given, which also correlated with changes in GPXI activity. These findings suggest that, in addition to GPX1, candidacidal activity of neutrophils is dependent on other selenium-dependent factors, including possibly phospholipid hydroperoxide GPX and cytosolic or mitochondrial TR.

It has been pointed out by Arthur et al. (2003) that the evidence for the foregoing views concerning neutrophil function in immunity relies on findings using in vitro cultures, and that it is highly likely that, in vivo, several other factors are involved. Thyroid hormone metabolism, for example, has been shown to play an important part in immune function. Hypothyroidism generally reduces the ability of neutrophils to respond to a challenge. Moreover, depression of thyroid function, by selenium deficiency, leading to a decrease in IDII, could lead to suboptimal development and function of thymic cells (Molinero et al., 1995).

Selenium is known to be essential for other aspects of cell-mediated immunity besides the destruction of pathogenic viruses and fungi, such as destruction of neoplastic cells. While GPX, in its role as protector against peroxides, must play a major part in such activities, it is unlikely that this is the only mediator of these functions of selenium. The anti-inflammatory role of selenium is also of importance. Both GPX and, possibly, the thioredoxin reductases also play a part by influencing eicosanoid metabolism to modulate inflammation. Fatty acids of the $(n-3)$ and (n-6) series act as substrates for the lipoxygenase pathway that gives rise to the leukotrienes, which are proinflammatory, and also for the cyclooxygenase pathway to the inflammatory prostaglandins and thromboxanes (McKenzie et al., 2000).

\subsubsection{Selenium and Inflammatory Diseases in Humans}

There is a limited amount of evidence from human studies which indicates that conditions associated with increased oxidative stress or inflammation may be related to dietary selenium intake. Low blood selenium levels occur in a number of inflammatory diseases, suggesting that selenium supplementation could be effective in their treatment. In rheumatoid arthritis, for instance, there is 
progressive erosion of joint cartilage that appears to be exacerbated by free radicals. Selenium supplementation has the potential to prevent this occurring by reducing the production and concentration of these reactive oxygen species. It was reported by Peretz et al. (1992) that short-term (3 months) supplementation with $200 \mu \mathrm{g} /$ day of selenium significantly reduced pain and joint involvement in a group of rheumatoid arthritis patients. In a large case-control study of Finnish subjects who had no arthritis at baseline, those in the highest tertile of serum selenium were found to have a lower risk of rheumatoid factor-negative arthritis than those in the lower tertile (Knekt, 2000). However, selenium supplementation has not been found to alleviate arthritic symptoms in some forms of arthritis.

Asthma is another condition in which oxidative stress and selenium deficiency have been identified as risk factors (Shaheen et al., 1999). The evidence for this, however, is not clear. While asthmatic adults have been shown to be protected against asthmatic wheeze, and clinical symptoms of children with intrinsic asthma improved on supplementation with selenium, some studies have found higher levels of GPX activity in blood of younger patients with asthma than in controls (Ward et al., 1984).

A UK study has shown that supplementation with selenium, and other antioxidants, can benefit patients suffering from pancreatitis by reducing pain and frequency of attacks (McCloy, 1998). It has also been reported that lethality from acute pancreatitis has been reduced by intravenous administration of selenite (Kuklinsky and Schweder, 1996). It is believed that the effect of the supplementation is to reduce the high level of oxidative stress associated with the disease.

\subsection{Selenium and Viral Infections}

It has been demonstrated by Beck and her colleagues that the association between viral disease and nutrition is due not only to the effects on the host's immune system but also to the fact that the host's nutritional status can have a direct effect on the viral pathogen itself (Beck, 1999). The group's interest in the relationship between infectious disease and host nutritional status began with their study of $\mathrm{KD}$. They noted that, though KD was found only in regions of China with selenium-poor soils, many of the features of the endemic cardiomyopathy, such as its seasonal and annual incidence, and the fact that not all selenium-deficient individuals developed $\mathrm{KD}$, could not be explained entirely on the basis of an inadequate intake of selenium. An infectious cofactor, possibly cocksackievirus, an enterovirus known to cause myocarditis, that had been isolated from the blood of KD victims was believed to be involved (Bai et al., 1979; Su et al., 1979). Beck and her colleagues used a mouse model to investigate the relationship between cocksackie infection and myocarditis (Beck et al., 1994). The mice were fed a diet deficient or adequate in selenium for 4 weeks and were then infected with either a benign strain of cocksackie B virus (CVB3/0), which was not known to cause cardiomyopathy, or with another strain (CVB3/20), which is myocarditic in 
mice. Both the selenium-deficient and the nondeficient mice injected with CVB3/20 developed myocarditis, as might have been expected, though symptoms were much more severe in the selenium-deficient than in the nondeficient animals, showing that the pathogenicity of the virus was increased by the deficiency. The results of infection with the benign strain CVB3/0 were unexpected. The selenium-adequate mice did not develop any myocarditis, as had been anticipated, while the selenium-deficient mice developed moderate myocarditis. Thus, the virulence of the normally benign virus was altered in the selenium-deficient animals-deficiency of selenium was seen to increase the pathogenicity of CVB3 virus, raising the severity of myocarditis caused by a virulent strain, and changing a normally benign strain into a virulent one (Beck, 1997). The same effects occurred in vitamin E-deficient mice and in GPX-knockout mice, which suggests that oxidative stress was involved in the mechanisms that caused the mutations in the virus (Beckett et al., 2003). It was also found that the change in virulence was due to specific mutations in the virus itself, such that once the mutation had occurred, even mice with normal nutrition became vulnerable to the virus (Beck et al., 1995).

The significance of these findings is considerable in relation to the occurrence, virulence, and disease progression of viral infections in general (Beck, 2001). The possibility that other viruses, such as poliovirus, hepatitis, influenza, or HIV, can also become more virulent by passing through a selenium-deficient host would have considerable public health implications. These, like coxsackievirus, are RNA viruses, and are prone to mutation in an oxidative environment (Beck, 1997) and in GPX-knockout mice (Beck et al., 1998). This is because RNA viruses, unlike DNA viruses, do not have proofreading enzymes, and thus genomic mistakes that occur in them cannot be repaired during replication (Steinhauer et al., 1992). It has been suggested that the emergence of new strains of influenza that has been reported in recent decades in China, a country with extensive regions of selenium-deficient soils, may be due to mutation of formerly less-virulent strains of the virus by passage through a low-selenium status population (Beckett et al., 2003). Beck et al. (2004) have stressed the urgent need to take particular account of the nutritional status of the host when investigating the emergence of new infectious diseases and of old diseases with new pathogenic properties, such as severe acute respiratory syndrome (SARS).

\subsubsection{Selenium, Human Immunodeficiency Virus, and Acquired Immunodeficiency Syndrome}

Selenium is believed to play a multifactorial role in human immunodeficiency virus (HIV) and acquired immunodeficiency syndrome (AIDS). A decline in blood selenium levels and GPX activity occurs in individuals with HIV and AIDS (Mantero-Atienza et al., 1991; Altavena et al., 1995). This decline begins in the early stages of HIV infection, when malnutrition and malabsorption are unlikely to be involved. 
Selenium deficiency is a recognized feature of advanced HIV disease, and may be due either to malnutrition and/or the presence of opportunistic infections (OI) (Look et al., 1997a). A low selenium status has been implicated in accelerated disease progression and poorer survival of HIV victims, especially pregnant women (Kupka et al., 2004). Plasma selenium levels are believed to be a strong predictor of the outcome of HIV infection (Baum et al., 1997). The fall in blood selenium is paralleled by a reduction in $\mathrm{CD} 4^{+} \mathrm{T}$-helper cells. These are cells that recognize viral antigen on the surface of infected cells and release chemotactic factors and cytokines that activate the cells to become resistant to the infection (Look et al., 1997b).

HIV, like certain other viruses, has the ability to acquire, through transduction, GPX-like genes that are believed to protect the virus from respiratory burst products of host neutrophils and macrophages. The use of GPX-like selenoproteins by the virus has been described as "hijacking" the selenium supply of the host by incorporating selenium into viral selenoproteins. The result is that the ability of the host to mount an effective immune response is reduced (Rayman, 2000). Several types of virus, including cocksackievirus B3 and measles, as well as HIV1, are known to have the ability to make viral, GPX-like, selenoproteins (Zhang et al., 1999).

The mechanisms that underlie the relationship between selenium status and HIV progression are not yet clear (Baum et al., 2001), and several studies of the mechanisms involved, as well as clinical trials to investigate the effect of supplementation on HIV, are currently being carried out. As has been noted by Semba and Tang (1999) in a report on the pathogenesis of human HIV, since $90 \%$ of those infected with HIV are in developing countries, it is especially important that micronutrient deficiencies be identified and trials be carried out to determine whether micronutrient supplementation will improve clinical outcomes.

\subsection{Selenium and Human Fertility}

Selenium is known to play a part in both males and females in reproduction. This has been long recognized in animal husbandry (Underwood, 1977; Hidiroglou, 1979). Low selenium blood levels have been associated with abortions in cattle and pigs (Stuart and Oehme, 1982). There are conflicting views on whether low selenium status is also implicated in infertility or miscarriages in humans. Evidence of significantly lower serum selenium in women who had either firsttrimester or recurrent miscarriages has been reported by one group (Barrington et al., 1997). However, a subsequent study failed to confirm this finding (Nicoll et al., 1999).

The evidence for a requirement of selenium for fertility is stronger for males than for females. Selenium has been shown, in animal experiments, to be an essential requirement for the synthesis of testosterone and normal development of spermatozoa (Behne et al., 1996). In the absence of adequate selenium, structural abnormalities occur in sperm and their motility is affected (Wu et al., 1973). It is 
believed that this is a result of a deficiency of GPX4, which in healthy animals accounts for about $50 \%$ of the sperm capsule material and confers the structural integrity necessary for sperm stability and motility (Ursini et al., 1999). Selenoprotein $\mathrm{P}$ has been shown to be required for the development of functional sperm in mice (Olson et al., 2005).

Investigations of the relation between selenium and fertility in humans also indicate the essential role of the element in spermatogenesis. In a group of subfertile Norwegian men, selenium levels in seminal plasma were found to be positively correlated with concentration of spermatozoa (Oldereid et al., 1998). However, while such results appear to support the view that selenium supplementation could improve fertility in subfertile men, this has not always been found to be the case. A Scottish study of subfertile men did find that supplementation with $100 \mu \mathrm{g}$ of selenium daily for 3 months resulted in significantly increased sperm motility and was followed by the fathering of a child in $11 \%$ of the group, compared to none in an unsupplemented control group (Scott et al., 1998). In contrast, a Polish study in which subfertile men were given a supplement of $200 \mu \mathrm{g} /$ day found that though there was an increase in selenium levels in seminal fluid, there was no increase in sperm fertility (Iwanier and Zachara, 1995).

\subsection{Selenium and Preeclampsia}

Preeclampsia, though not directly a problem of infertility, is another condition related to fertility, believed to be associated with low selenium status. The disease is a major problem of pregnancy, with a high maternal and perinatal morbidity and mortality (Rayman et al., 2003). Placental ischemia and oxidative stress, resulting from poor placentation (Redman and Sargent, 2000), are believed to produce bloodborne agents that cause a maternal systemic inflammatory response and generalized endothelial dysfunction. This gives rise to the characteristic symptoms of hypertension, protinurea, and sudden edema (Roberts et al., 1989). The bloodborne agents are believed to be the products of oxidative stress (Redman et al., 1999). A recent study has found evidence indicating that elevated lipid peroxide levels, impaired antioxidant defense mechanisms, and lower trace element status may be related at least partly to the pathogenesis of preeclampsia (Atamer et al., 2005).

There is evidence that the peroxynitrite may play a major role in the endothelial dysfunction and the resulting oxidative stress of preeclampsia. Peroxynitrite is a potent inflammatory mediator, and causes vasoconstriction, platelet aggregation, and thrombus formation (Arteel et al., 1999). It occurs in the placenta of all women, but is produced to a significantly greater extent in those with preeclampsia (Myatt et al., 1996).

It has been shown that supplementation with the antioxidants vitamins $C$ and $\mathrm{E}$ can reduce the incidence of preeclampsia in women with a high risk of the disease (Chappell et al., 1999). Another study looked at the possibility that selenoproteins, which are known to be able to limit adverse endothelial effects, 
with selenoprotein $\mathrm{P}$ having a unique capacity for scavenging peroxynitrite at the endothelial surface (Anteel et al., 1999), could have similar effect. When the selenium status of a group of preeclampsic (assessed by toenail clippings) patients was compared with that of a matched group of nonpreeclampsic women, it was shown that the former had a significantly lower selenium status than had the controls. Being in the lower tertile of toenail selenium was associated with a 4.4-fold greater incidence of the disease, and within the preeclampsic group, lower selenium status was significantly associated with more severe expression of the disease (Rayman et al., 2003).

These findings have not provided clear evidence that selenium deficiency is a cause of preeclampsia, though they do indicate that there is a connection between low selenium status and the condition. This conclusion is given some support by the results of a small-scale Chinese study in which selenium supplementation (at $100 \mu \mathrm{g} /$ day) was shown to prevent pregnancy-induced hypertension and gestational edema in women at risk of developing hypertension (Han and Zhou, 1991). A further trial, to test the hypothesis that an adequate selenium status is important for antioxidant defense and peroxynitrite scavenging in pregnant women at risk of preeclampsia, is planned in the UK (Rayman et al., 2003).

\section{References}

Altavena, C., Dousset, B., May, T., et al., 1995, Relationship of trace element, immunological markeres, and HIV1 infection progression, Biol. Trace Elem. Res. 47, 133-138.

Arteel, G.E., Briviba, K., and Sies, H., 1999, Protection against peroxynitrite, FEBS Lett. $115,226-230$.

Arthur, J.R., McKenzie, R.C., and Beckett, G.J., 2003, Selenium in the immune system, J. Nutr. 133, 1457S-1459S.

Arvilommi, H., Poikonen, K., Jokinen, I., et al., 1983, Selenium and immune functions in humans, Infect. Immun. 41, 185-189.

Atamer, Y., Kocyigit, Y., Yokus, B., et al., 2005, Lipid peroxidation, antioxidant defense, status of trace metals and leptin levels in preeclampsia, Eur. J. Obstet. Gynecol. Reprod. Biol. 119, 60-66.

Bai, J., Wu, S., Ge, K., et al., 1979, Preliminary results of viral etiology of Keshan disease, Chin. Med. J. 59, 466-472.

Barrington, J.W., Taylor, M., Smith, S., and Bowen-Simpkins, P., 1997, Selenium and recurrent miscarriage, J. Obstet. Gynaecol. 17, 199-200.

Baum, M.K., Shor-Posner, G., Lai, S., et al., 1997, High risk of HIV-related mortality is associated with selenium deficiency, J. Acquir. Immune Defic. Syndr. 15, 370-374.

Baum, M.K., Campa, A., Miguez-Burbano, M.J., et al., 2001, Role of selenium in HIV/AIDS, in: Hatfield, D.L. (ed.), Selenium: Its Molecular Biology and Role in Health, Kluwer Academic, Boston, MA, pp. 232-235.

Beck, M., 2001, Selenium as an antiviral agent, in: Hatfield, D.L. (ed.), Selenium: Its Molecular Biology and Role in Health, Kluwer Academic, Boston, MA, pp. 235-245.

Beck, M.A., 1997, Rapid genomic evolution of a non-virulent coxsackievirus B3 in selenium-deficient mice, Biomed. Environ. Sci. 10, 307-315.

Beck, M.A., 1999, Selenium and host defense towards viruses, Proc. Nutr. Soc. 58, 707-711. 
Beck, M.A., Shi, Q., Morris, V.C., and Levander, O.A., 1995, Rapid genomic evolution of nonvirulent cocksackievirus B3 in selenium deficient mice results in selection of identical virulent isolates, Nat. Med. 1, 433-436.

Beck, M.A., Esworthy, R.S., Ho, Y.S., and Chu, F.F., 1998, Glutathione peroxidase protects mice from viral-induced myocarditis, FASEB J. 12, 1143-1149.

Beck, M.A., Handy, J., and Levander, O.A., 2004, Host nutritional status: the neglected virulence factor, Trends Microbiol. 12, 417-423.

Beckett, G.J., Arthur, J.R., Miller, S.M., and McKenzie, R.C., 2003, Selenium, in: Hughes, D.A., Darlington, G., and Bendich, A. (eds), Dietary Enhancement and Human Immune Function, Humana Press, Totowa, NJ, pp. 217-240.

Behne, D., Weiler, H., and Kyriamopoulos, A., 1996, Effects of selenium deficiency on testicular morphology and function in rats, J. Reprod. Fertil. 106, 291-297.

Boyne, R. and Arthur, J.R., 1986, The response of selenium deficient mice to Candida albicans infection, J. Nutr. 116, 816-822.

Boyne, R., Mann, S.O., and Arthur, J.R., 1984, Effects of Salmonella typhimurium infection on selenium deficient rats, Microbios Lett. 27, 83-87.

Brown, K.M. and Arthur, J.R., 2001, Selenium, selenoproteins and human health: a review, Public Health Nutr. 4, 593-599.

Chappell, I.C., Seed, P.T., Briely, A.I., et al., 1999, Effect of antioxidants on the occurrence of preeclampsia in women at increased risk: a randomised trial, Lancet 351, 810-816.

Eskew, M.L., Scholz, R.W., Reddy, C.C., et al., 1985, Effects of vitamin E and selenium deficiencies on rat immune function, Immunology 54, 173-180.

Han, I. and Zhou, S., 1991, Selenium supplementation in the prevention of pregnancy induced hypertension, Chin. Med. J. 107, 870-871.

Hidiroglou, M., 1979, Trace element deficiencies and fertility in ruminants: a review, J. Dairy Sci. 62, 1195-1206.

Iwanier, K. and Zachara, B., 1995, Selenium supplementation enhances the element concentration in blood and seminal fluid but does not change the spermatozoal quality characteristics in subfertile men, J. Androl. 16, 441-447.

Khalil, A.M., 1989, The induction of chromosome aberrations in human purified peripheral blood lymphocytes following in vivo exposure to selenium, Mutat. Res. 224, 503-506.

Kiremidjian-Schumacher, L. and Roy, M., 1998, Selenium and immune function, Z. Ernahrungswiss. 37, 50-56.

Kiremidjian-Schumacher, L., Roy, M., Wishe, H., et al., 1994, Supplementation with selenium and human immune cell functions. II. Effect on cytotoxic lymphocytes and natural killer cells, Biol. Trace Elem. Res. 41, 115-127.

Knekt, P., Heliövaara, M., Aho, K., et al., 2000, Serum selenium, serum alpha-tocopherol and the risk of rheumatoid arthritis, Epidemiology 11, 402-405.

Kuklinsky, B. and Schweder, R., 1996, Acute pancreatitis, a free radical disease: reducing the lethality with sodium selenite and other antioxidants, J. Nat. Environ. Med. 6, 393-394.

Kupka, R., Msamanga, G.I., Spiegelman, D., et al., 2004, Selenium status is associated with accelerated HIV disease progression among HIV-1-infected pregnant women in Tanzania, J. Nutr. 134, 2556-2560.

Larsen, H.J. and Tollersrud, S., 1981, Effect of dietary vitamin E and selenium on the phytohemoglutinin response of pig lymphocytes, Res. Vet. Sci. 31, 301-305.

Larsen, H.J., Moksnes, K., and Overnes, G., 1988, Influence of selenium on antibody production in sheep, Res. Vet. Sci. 45, 4-10. 
Larsen, H.J.S., 1993, Relations between selenium and immunity, Norwegian J. Agric. Sci. Suppl. 11, 195-119.

Look, M.P., Rocstroh, J.K., Rao, G.S., et al., 1997a, Serum selenium, plasma glutathione (GSH) and eryhtrocyte glutathione peroxidase (GSH-Px)-levels in asymptomatic versus symptomatic human immunodeficiency virus-1 (HIV-1)-infection, Eur. J. Clin. Nutr. 51, 266-272.

Look, M.P., Rockstroh, J.K., Rao, G.S., et al., 1997b, Serum selenium versus lymphocyte subsets and markers of disease progression and inflammatory response in human immunodeficiency virus-infection, Biol. Trace Elem. Res. 56, 31-41.

Mantero-Atienza, E., Beach, R.S., Gavancho, M.C., et al., 1991, Selenium status of HIV1 infected individuals, J. Parent. Ent. Nutr. 15, 693-694.

Marsh, J.A., Combs, G.F., Whiteacre, M.E., and Dietert, R.R., 1986, Effect of selenium and vitamin E deficiencies on chick lymphoid organ developments, Proc. Soc. Exp. Biol. Med. 182, 425-436.

Marsh, J.A., Dietert, R.R., and Combs, G.F., 1987, Effect of dietary selenium and vitamin E deficiencies in the chicken on Con A-induced splenocyte prolifereation, Prog. Clin. Biol. Res. 238, 333-345.

Maurer, P.H., 1961, Immunology, in: Gray, P. (ed.), Encyclopedia of the Biological Sciences, Reinhold, New York, pp. 503-505.

McCloy, R., 1998, Chronic pancreatitis in Manchester, UK: focus on antioxidant therapy, Digestion 59 (Suppl. 4), 36-48.

McKenzie, R.C., Arthur, J.R., Miller, S.M., et al., 2000, Selenium and the immune system, in: Calder, P.C., Field, C.J., and Gill, N.S. (eds), Nutrition and Immune Function, CAB International, Oxford, pp. 229-250.

Molinero, P., Osuna, C., and Guerrero, J.M., 1995, Type I thyroxine 5'-deiodinase in the rat thymus, J. Endocrinol. 146, 816-822.

Montgomery, R., Dryer, R.L., Conway, T.W., and Spector, A.A., 1977, Biochemistry, a Case-Orientated Approach, 2nd edn., Mosby, St Louis, MO, pp. 65-67.

Mulhern, S.A., Taylor, G.L., Magruder, L.E., and Vessey, A.R., 1985, Deficient levels of dietary selenium suppress the antibody response in first and second-generation mice, Nutr. Res. 5, 201-210.

Myatt, I., Rosenfield, R.B., Eis, A.I., et al., 1996, Nitrotyrosine residues in placenta. Evidence for peroxynitite formation and action, Hypertension 28, 188-193.

Nicoll, A.E., Norman, J., McPherson, A., and Acharya, U., 1999, Association of reduced selenium status in the aetiology of recurrent miscarriage, Br. J. Obstet. Gynaecol. 106, $1188-1191$.

Oldereid, N.B., Thomassen, Y., and Purvis, K., 1998, Selenium in human males reproductive organs, Hum. Reprod. 13, 2172-2176.

Olson, G.E., Winfey, V.P., NadDas, N.K., Hill, K.E., and Burk, R.F., 2005, Selenoprotein $\mathrm{P}$ is required for mouse sperm development, Biol. Reproduct. 73, 201-211.

Peretz, A., Nève, J., Duchataeu, J.P., and Famaey, J.P., 1992, Adjuvant treatment of recent onset rheumatoid arthritis by selenium supplementation: preliminary observations, Br. J. Rheumatol. 31, 281-286.

Rayman, M.P., 2000, The importance of selenium to human health, Lancet, 356, 233-241.

Rayman, M.P., Bode, P., and Redman, C.W.G., 2003, Low selenium status is associated with the occurrence of the pregnancy disease preeclampsia in women from the United Kingdom, Am. J. Obstet. Gynecol. 189, 1343-1349.

Redman, C.W.G. and Sargent, H., 2000, Placental debris, oxidative stress and preeclampsia, Placenta 21, 597-602. 
Roberts, J.M., Taylor, R.N., Musci, T.J., et al., 1989, Preeclampsia: an endothelial cell disorder, Am. J. Obstet. Gynecol. 161, 1200-1201.

Scott, R. and McPherson, A., 1998, Selenium supplementation in sub-fertile human males, Br. J. Urol. 82, 625-629.

Semba, R.D. and Tang, A.M., 1999, Micronutrients and the pathogenesis of human immunodeficiency virus infection, Br. J. Nutr. 81, 181-189.

Serfass, R.E. and Ganther, H.E., 1975, Defective microbiocidal activity in glutathione peroxidase deficient neutrophils of Se deficient rats, Nature (Lond.), 225, 640-641.

Shaheen, S.O., Sterne, J.A.C., Thompson, R.L., et al., 1999, Dietary antioxidants and asthma in adults, Eur. Respir. J. 14 (Suppl. 30), 141-150.

Spallholz, J.E., 1990, Selenium and glutathione peroxidase: essential nutrient and antioxidant component of the immune system, Adv. Exp. Med. Biol. 262, 145-158.

Spallholz, J.E., Martin, J.L., Gerlach, M.L., and Heizerling, R.H., 1975, Injectable selenium: effect on the primary immune response of mice, Proc. Soc. Exp. Biol. Med. 148, 37-40.

Staines, N.A., Brostoff, J., and James, K., 1993, Introducing Immunology, 2nd edn., Mosby, St Louis, MO.

Steinhauer, D., Domingo, E., and Holland, J.J., 1992, Lack of evidence for proofreading mechanisms associated with an RNA virus polymerase Gene 122, 281-288.

Stuart, L.D. and Oehme, F.W., 1982, Environmental factors in bovine and porcine abortion, Vet. Hum. Toxicol. 24, 435-441.

Su, C., Gong, C., Li, J., et al., 1979, Preliminary results of viral etiology study of Keshan disease, Chinese Med. J. 59, 466-472, cited in Ge, K. and Yang, G., 1993, The epidemiology of selenium deficiency in the etiology of endemic diseases in China, Am. J. Clin. Nutr. Suppl. 57, 259S-263S.

Turner, R.J. and Finch, J.E., 1990, Immunological malfunctions associated with low selenium-vitamin E diets in lambs, J. Compar. Pathol. 102, 99-109.

Turner, R.J. and Finch, J.M., 1991, Selenium and the immune response, Proc. Nutr. Soc. 50, 275-285.

Underwood, E.J., 1977, Trace Elements in Human and Animal Nutrition, 4th edn., Academic Press, New York, pp. 303-345.

Ursini, F., Heim, S., Kiess, M., et al., 1999, Dual function of the selenoprotein PHGPx during sperm maturation, Science 285, 1393-1396.

Ward, K.P., Arthur, J.R., Russell, G., and Aggett, P.J., 1984, Blood selenium content and glutathione peroxidase activity in children with cystic fibrosis, coeliac disease, asthma and epilepsy, Eur. J. Paediatr. 142, 21-24.

Whanger, P.D., Weswig, P.H., and Oldfield, J.E., 1978, Selenium, sulfur and nitrogen levels in ovine rumen microorganisms, J. Anim. Sci. 46, 515-519.

Wu, S.H., Oldfield, J.E., Whanger, P.D., and Weswig, P.H., 1973, Selenium and reproduction in sheep, Biol. Reprod. 8, 625-629.

Zhang, W., Ramanathan, C.S., Nadimpalli, R.G., et al., 1999, Selenium-dependent glutathione peroxidase modules encoded by RNA viruses, Biol. Trace Elem. Res. 70, 97-116. 